
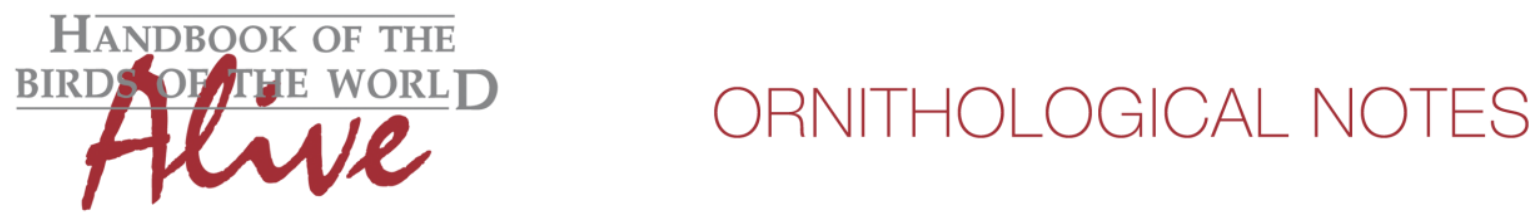

\title{
Notes on the vocalizations of Spotted Woodcreeper (Xiphorhynchus erythropygius)
}

Peter Boesman

In the following we briefly analyze and compare song of the different races of Spotted Woodcreeper (Xiphorhynchus erythropygius). We also try to quantify the extent of any vocal differences using the criteria proposed by Tobias et al. (2010), as a support for taxonomic review.

We have made use of sound recordings available on-line from Xeno Canto (XC) and Macaulay Library (ML).

The song of all races is a series of 2-4 (occasionally 5) slowly delivered whistles, every whistle slightly lower pitched than the previous.

We can however distinguish two groups:

"northern group" (includes erythropygius and parvus)

Every whistle is pure (without burry or quavering tonal quality), downslurred with a small rise at the very beginning. Sonogram shape of all notes very similar (Fig. 1).
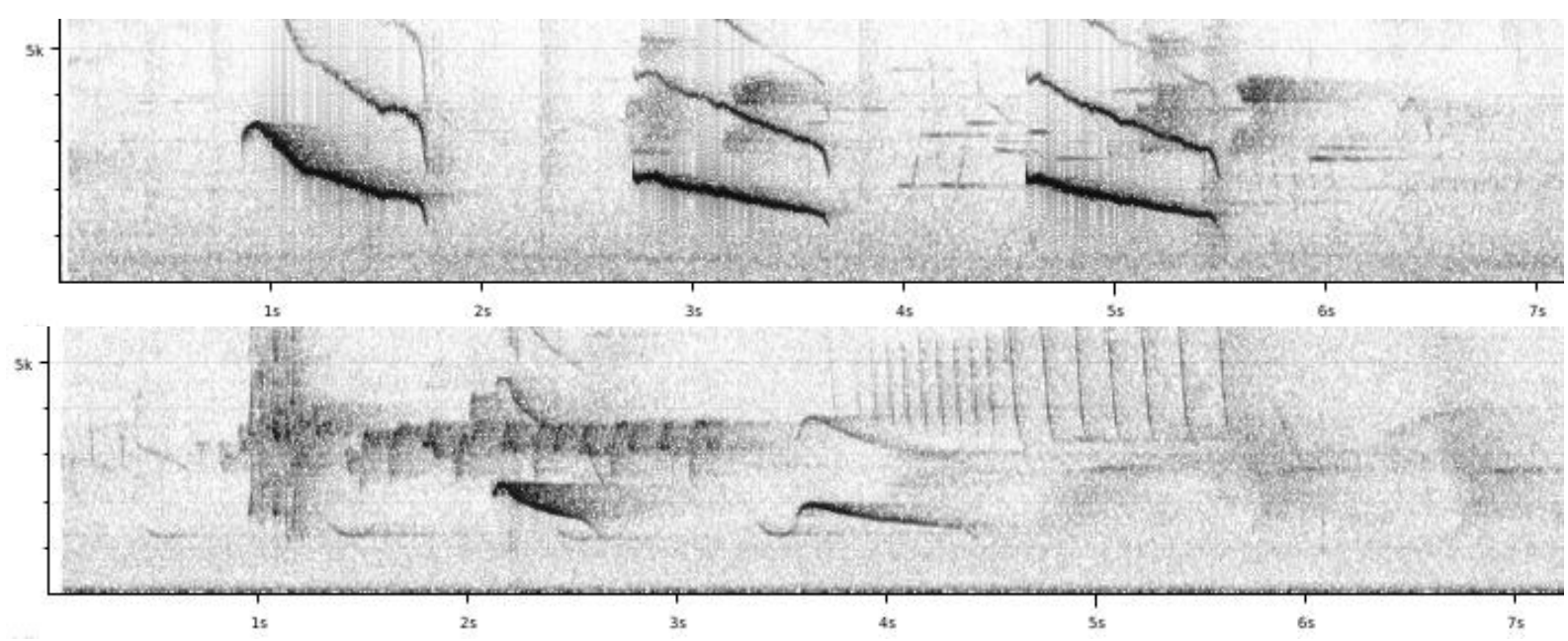

Figure 1: example of song of erythropygius (above) and parvus (below)

Measurements:

Max. freq first whistle:

$2400-2900 \mathrm{~Hz}$

Max. frequency second whistle:

$2000-2300 \mathrm{~Hz}$

Frequency drop between first two whistles:

$400-700 \mathrm{~Hz}$

Location of max. frequency in second whistle:

$0.05-0.07 \mathrm{~s}$ 


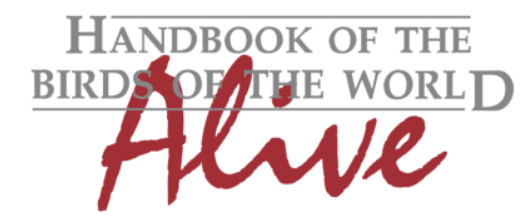

\section{ORNITHOLOGICAL NOTES}

"southern group" (including aequatorialis, punctigula and insolitus)

At least one whistle has a burry or quavering tonal quality (this is most outspoken in aequatorialis where all whistles are very quavering, so there is clearly a gradual trend here from $\mathrm{N}$ to $\mathrm{S}$ ). The first whistle is downslurred with a rise at the very beginning, but the second and subsequent whistles are overslurred, sonogram shape of first and subsequent notes is thus quite different (Fig.2). Whistles on average higher-pitched than previous group, especially from second note onwards.
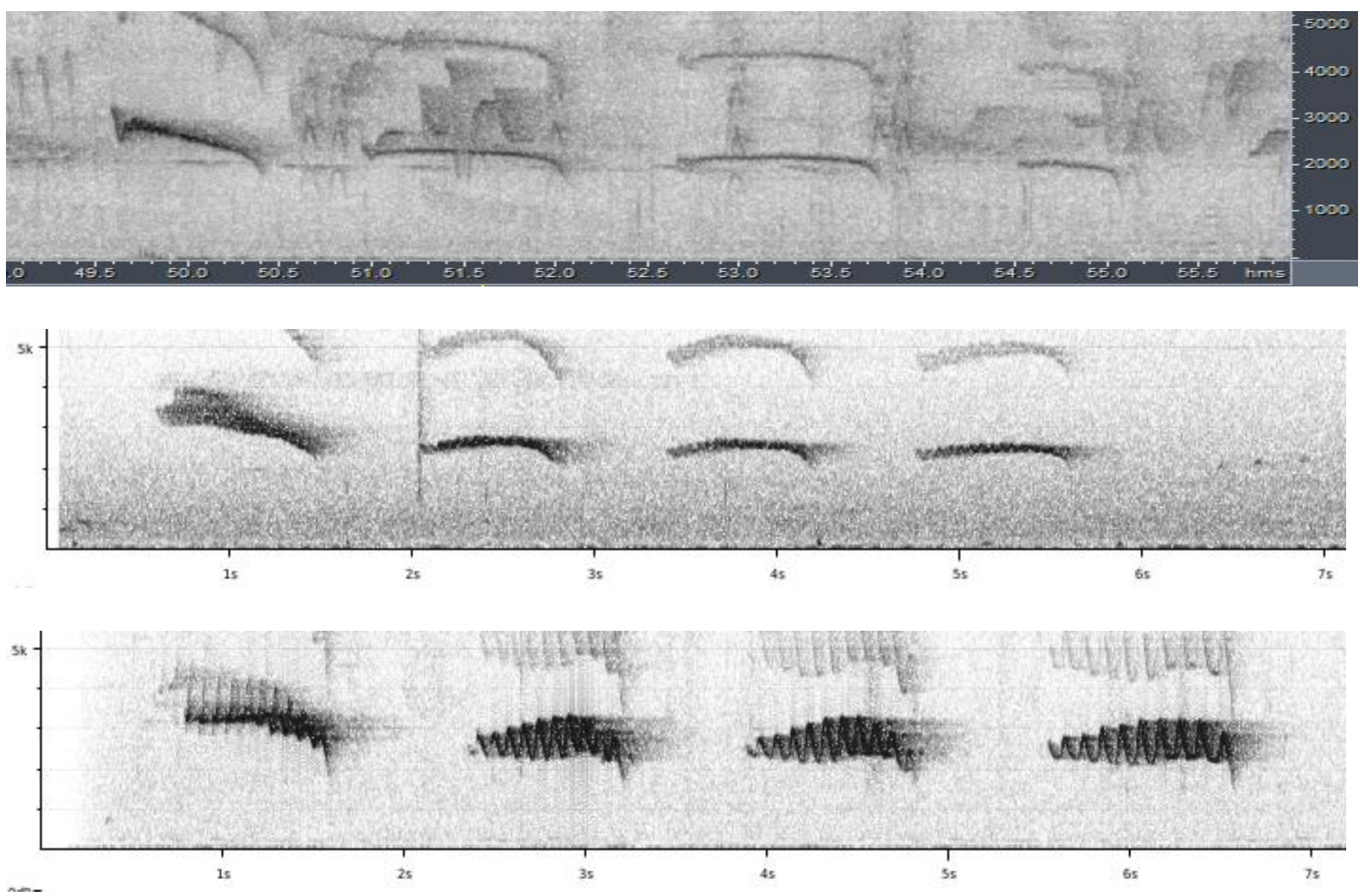

Figure 2: example of song of puctigula (above), insolitus (middle) and parvus (below)

Measurements:

Max. freq first whistle:

$2900-3700 \mathrm{~Hz}$

Max. frequency second whistle:

$2700-3300 \mathrm{~Hz}$

Frequency drop between first two whistles:

$200-900 \mathrm{~Hz}$

Location of max. frequency in second whistle:

$0.22-0.5 \mathrm{~s}$

Quantifiable differences in song are the max. frequency of the first whistle (slightly lower in northern group, score 1-2), max. frequency of second whistle (lower in northern group, score 2 ), location of max. frequency in second whistle (downslurred thus at very start in northern group, score 2 or 3 ) and qualitatively, the more burry notes of southern group (although this is clearly more outspoken in southern races). This leads to a total score according to Tobias criteria of 4 or 5 .

Analysis of call may (or may not) reveal additional differences. 
This note was finalized on 3rd April 2015, using sound recordings available on-line at that moment. We would like to thank in particular the many sound recordists who placed their recordings for this species on XC and ML.

\section{References}

Tobias, J.A., Seddon, N., Spottiswoode, C.N., Pilgrim, J.D., Fishpool, L.D.C. \& Collar, N.J. (2010). Quantitative criteria for species delimitation. Ibis 152(4): 724-746.

\section{Recommended citation}

Boesman, P. (2016). Notes on the vocalizations of Spotted Woodcreeper (Xiphorhynchus erythropygius). HBW Alive Ornithological Note 82. In: Handbook of the Birds of the World Alive. Lynx Edicions, Barcelona. (retrieved from http://www.hbw.com/node/931976 on 16 July 2016). 